\title{
Evaluation of Analytical Performance of the D-100 Hemoglobin Testing System for Hemoglobin A1c
} Assay

Kyunghoon Lee ${ }^{1,2}$, Sung Min $\mathrm{Kim}^{3}$, Sun Hee Jun ${ }^{3}$, Sang Hoon Song ${ }^{1,2}$, Kyoung Un Park ${ }^{1,3}$, and Junghan Song ${ }^{1,3}$

${ }^{1}$ Department of Laboratory Medicine, Seoul National University College of Medicine; ${ }^{2}$ Department of Laboratory Medicine, Seoul National University Hospital, Seoul; ${ }^{3}$ Department of Laboratory Medicine, Seoul National University Bundang Hospital, Seongnam, Korea

Corresponding author: Junghan Song Department of Laboratory Medicine, Seoul National University Bundang Hospital, 82 Gumi-ro 173 beon-gil, Bundanggu, Seongnam 13620, Korea Tel: $+82-31-787-7691$ Fax: +82-31-787-4015 E-mail: songjhcp@snu.ac.kr

pISSN: 2384-2458 eISSN: 2288-7261
Background: The hemoglobin Alc (HbAlc) level is widely used to diagnose and monitor glycaemic control in people with diabetes mellitus, and various methods are used for its determination. The D-100 hemoglobin testing system (Bio-Rad Laboratories, USA) is a fully automated, high-throughput glycohaemoglobin analyzer based on an ion-exchange highperformance liquid chromatographic method. Here, we evaluated the analytical performance of a newly developed $\mathrm{HbAlc}$ analyzer.

Methods: Precision, linearity, and comparison to the Variant II Turbo analyzer (Bio-Rad Laboratories, USA) were evaluated according to the Clinical Laboratory Standards Institute guidelines. Carryover, bias from the value assigned by the HbA1c Network Laboratory of Korea Centers for Disease Control and Prevention, and the vulnerability to interference by hemoglobin variants frequently found in Korea were also assessed. Statistical analyses were performed using Excel 2010 (Microsoft Co., USA) and MedCalc ver. 14.12.0 (MedCalc Software bvba, Belgium).

Results: The coefficients of variation for repeatability and within-device precision were less than $1.08 \%$ in National Glycohaemoglobin Standardization Program (NGSP) unit and less than $1.68 \%$ in international system of unit at all three levels. The calibration curve was linear, with $\mathrm{R}^{2}=0.996$ in the range of $4.6 \%$ to $15.4 \%$ in NGSP unit. The results highly correlated with those produced by Variant II Turbo ( $r=0.998)$. The 95\% confidence interval for differences from the assigned values was $-3.3 \%$ to $2.9 \%$. No significant interferences of haemoglobin variants were observed except for Hemoglobin Yamagata.

Conclusions: The D-100 hemoglobin testing system showed excellent precision, linearity, and good correlation with the Variant II Turbo analyzer and agreement with the assigned values. Therefore, its analytical performance is satisfactory for diabetes diagnosis and treatment monitoring.

(J Lab Med Qual Assur 2016;38:95-101)

Key Words: Glycated hemoglobin, Hemoglobin A1c, Analytical performance, Diabetes mellitus, High pressure liquid chromatography

Received January 15, 2016, Revision received April 29, 2016, Accepted May 11, 2016
서론

전 세계적으로 당뇨병의 유병률은 계속적으로 증가하고 있 다. 2004년도의 보고에 의하면 2030년에는 3 억5천만 명까지 증가할 것이라고 추정하였으나[1], 이미 2014년도에 3억8천7 백만 명에 도달하였다. 우리나라의 경우 질병관리본부에서 30 세 이상 성인을 대상으로 2007년부터 2010년도까지 시행한
국민건강영양조사 자료에 의하면 당뇨병 유병률은 $10.1 \%$, 당 뇨병 전 단계인 공복혈당장애 유병률은 $19.9 \%$ 이었고, 2050 년도 우리나라 당뇨병 환자 수는 약 600만 명으로 늘어날 것 이라고 추정하고 있다[2]. 혈중 당화혈색소(hemoglobin A1c, $\mathrm{HbA} 1 \mathrm{c})$ 는 최근 약 3 개월간의 평균 혈당치를 반영하기 때문 에 환자의 혈당상태를 파악하여 당뇨병의 진단, 치료효과 판 정 및 모니터링에 중요한 역할을 하는 검사이다[3]. 따라서 당 


\section{Journal of LABORATORY MEDICINE and QUALITY ASSURANCE}

Kyunghoon Lee et al • Performance Evaluation of D-100 HbA1c System

뇨병 환자의 정확한 진단과 치료지침 결정을 위해서는 정확 한 검사결과가 필수적이기 때문에 $\mathrm{HbAlc}$ 검사결과의 표준 화(standardization)를 위해 전 세계적으로 많은 노력이 진 행돼 오고 있다[4,5]. 우리나라에서는 대한임상정도관리협회 가 2007년 $\mathrm{HbA1c}$ 의 신빙도조사를 시작하였고, 2009년부터 는 표준방법으로 측정한 참값을 기준으로 평가하는 정확도에 기반하는 신빙도조사를(accuracy-based proficiency testing) 시행하고 있다[6]. 2012년 이전에는 참값을 구하기 위해 외 국 표준검사기관에 검사를 의뢰하였는데, 2012년 10월에 우 리나라 질병관리본부의 국가표준의학검사실이 International Federation of Clinical Chemistry HbA1c Network Laboratory로 승인받은 이후에는 국내에서도 참값 측정이 가 능해지는 등 $\mathrm{HbAlc}$ 검사결과의 표준화를 위한 사업이 활발히 진행되고 있다.

$\mathrm{HbAlc}$ 측정법을 검사원리에 따라서 이온교환 고성능액체 크로마토그래피법(ion-exchange high-performance liquid chromatography), 면역측정법(immunoassay), 그리고 친 화크로마토그래피법(affinity chromatography)으로 크게 3 가지로 구분할 수 있다. 최근에 개발된 D-100 hemoglobin testing system (D-100 system; Bio-Rad Laboratories Inc., Hercules, CA, USA)는 이온교환 고성능액체크로마토크래피 법를 이용한 $\mathrm{HbA1c}$ 자동분석장비로 이에 대한 분석능력 및 유용성에 대한 평가는 국내에 아직 보고되지 않았다. 그리하 여 D-100 system에 대한 정밀도, 직선성, 검체 간 교차오염률, 상관성, 질병관리본부 국가표준진단의학검사실에서 측정한 참값과 일치도, 헤모글로빈 변이형(hemoglobin variant)이 미 치는 영향을 평가함으로써 임상검사실에서의 유용성을 확인 하고자 하였다.

\section{재료 및 방법}

본 연구는 2014년 11월 14일 분당서울대학교병원의 임상연 구심의위원회(institutional review board) 심의를 얻어 진행 되었다(승인번호: B-1410-272-303).

\section{1. 검체}

2015년 3월부터 4월까지 분당서울대학교병원에서 $\mathrm{HbA1c}$ 검사결과 보고 후 남은 잔여 검체 총 197 개, 질병관리본부 국 가표준진단의학검사실에서 측정한 참값이 있는 $\mathrm{HbA1c}$ 검 체 48개, 그리고 분당서울대학교병원을 포함한 4 개의 병원에 서 $\mathrm{HbAlc}$ 분석장비에서 헤모글로빈 변이형이 의심되었던 검 체 중 DNA 서열분석을 통하여 확인한 14검체(hemoglobin
Chad 2개, hemoglobin Fort de France 1개, hemoglobin Yamagata 1개, Hemoglobin G-Coushatta 10개)를 이용하여 평가하였다.

\section{2. 장비 및 시약}

HbA1c는 D-100 system과 Variant II Turbo（Bio-Rad Laboratories) 장비를 사용하여 EDTA 전혈 검체로 측정하였 다. 검사는 각 제조회사의 지침에 따라 시행하였으며, 모두 제 조사 전용 키트의 동일한 로트 시약을 사용하였다.

\section{3. 정밀도}

정밀도는 Clinical and Laboratory Standard Institute (CLSI) EP05-A3 지침에 따라 낮은 농도, 중간 농도, 높은 농 도의 환자 검체를 각각 하루에 2 회씩 반복하여 20 일간 측정하 여 평가하였다[7]. Repeatability, 검사일 간 정밀도와 검사기 기 내(within-device) 정밀도의 변이계수를 구하였다.

\section{4. 직선성}

직선성은 CLSI EP06-A에 따라 Variant II Turbo 장비에서, $4.6 \%$ 의 낮은 $\mathrm{HbAlc}$ 농도를 보이는 검체와 $15.4 \%$ 의 높은 농 도를 보이는 검체를 각각 $0: 4,1: 3,2: 2,3: 1,4: 0$ 으로 혼합하 여 조제한 5 개 농도의 검체를 각각 4 회씩 반복하여 측정하였 다[8]. 선형회귀분석을 이용하여 회귀방정식과 결정계수 $\left(\mathrm{R}^{2}\right)$ 를 각각 구하였다.

\section{5. 검체 간 교차오염률}

높은 $\mathrm{HbA} 1 \mathrm{c}$ 농도 검체와 낮은 농도 검체를 4 회 연속 측정하 여 검체 간 교차오염률을 확인하였다. 식 \%carryover $=[\mathrm{L} 1-$ $(\mathrm{L} 3+\mathrm{L} 4) / 2] \times 100 /[(\mathrm{H} 2+\mathrm{H} 3) / 2-(\mathrm{L} 3+\mathrm{L} 4) / 2]$ 를 이용하여 계산하였으며, $1.0 \%$ 를 기준치로 선정하였다.

\section{6. 상관성}

상관성 평가는 CLSI EP09-A3 지침에 따라 수행하였다[9]. $\mathrm{HbA} 1 \mathrm{c}$ 농도가 4.8\%-12.3\% 범위 안의 환자 검체 190 개를 선 정하여 Variant II Turbo와 D-100 system 장비로 각각 측정 하였고, Passing-Bablok 회귀분석으로 Pearson 상관계수(r) 와 상관방정식을 구하였으며, Bland-Altman agreement 분 석을 실시하였다.

\section{Hemoglobin A1c 참값과 일치도 평가}

질병관리본부 국가표준진단의학검사실에서 측정한 $\mathrm{HbAlc}$ 참값을 알고 있는 48검체를 이용하여 참값과의 일치도를 평 


\section{Journal of LABORATORY MEDICINE and QUALITY ASSURANCE}

Kyunghoon Lee et al • Performance Evaluation of D-100 HbA1c System

가하였다. 참값과 D-100 system에서 측정한 값의 일치도 평 가를 위하여 Passing-Bablok 회귀분석과 Bland-Altman agreement 분석을 실시하였다.

\section{8. 헤모글로빈 변이형 검체의 평가}

$\mathrm{DNA}$ 염기서열분석을 통하여 확인된 총 14 검체를 이용하 여 질병관리본부 국가표준진단의학검사실에서 측정한 값과 D-100 system에서 나오는 결과값 및 flag를 확인하였다.

\section{9. 통계분석}

통계분석은 Microsoft Excel 2010 (Microsoft Co., Redmond, WA, USA)과 MedCalc ver. 14.12.0 (MedCalc Software bvba, Ostend, Belgium) 프로그램을 사용하였다.

\section{결과}

Repeatability의 변이계수와 검사기기 내 정밀도의 변이계 수는 international system of unit $(\mathrm{mmol} / \mathrm{mol})$ 을 적용하였 을 때 1.05\%-1.68\%이었으며, National Glycohaemoglobin Standardization Program (NGSP) unit (\%)을 적용하였을 때 0.80\%-1.08\%이었다(Table 1). 직선성 검증을 위해 5 가 지 농도의 검체를 4회 반복 측정한 결과, $4.6 \%-15.4 \% \mathrm{HbA1c}$ 농도 범위에서 결정계수 $\left(\mathrm{R}^{2}\right)$ 가 0.996 이었으며, 회귀방정식은 $\mathrm{y}=0.9849 \mathrm{x}$ 이었다(Fig. 1). 높은 농도 검체(18.9\%)와 낮은 농 도 검체 $(3.8 \%)$ 를 각각 4 회 연속 측정하여 계산한 검체 간 교 차오염률은 $0.65 \%$ 였다.

Variant II Turbo와 D-100 system에서 동시에 2번 반복 측정한 $\mathrm{HbAlc}$ 농도는 4.8\%-12.3\% 범위에서 우수한 상관 성을 보였다 $(\mathrm{r}=0.998)$. Passing-Bablok 회귀분석을 시행하 여 얻은 $\mathrm{y}=0.954 \mathrm{x}+0.187$ 의 상관식을 얻었다(Fig. 2). 질병 관리본부 국가표준진단의학검사실에서 측정한 참값과 D-100 system에서 측정한 결과 간의 Bland-Altman plot에서 결
과값 $\%$ bias의 평균은 - $-2.2 \%$ 였고, $95 \%$ 신뢰구간은 - $3.3 \%$ $2.9 \%$ 였다(Fig. 3).

14 개의 헤모글로빈 변이형 검체를 측정하였을 때 hemoglobin G-Coushatta 10검체의 bias 평균과 표준편차 는 $-0.28 \% \pm 0.24 \%$ (NGSP unit)이었다. Hemoglobin Chad 2검체와 hemoglobin Fort de France 1검체의 bias는 각각 $0.10 \%,-0.08 \%, 0.16 \%$ 였다. 그러나 hemoglobin Yamagata 1검체의 bias는 $30.08 \%$ (NGSP unit)였다.

\section{고찰}

본 연구에서는 D-100 system의 정밀도, 직선성, 검체 간 교 차오염률을 통하여 분석능을 평가하였다. Repeatability와 검 사기기 내 정밀도의 결과를 보면 미국임상화학회에서 당뇨병 에 관련한 임상검사지침에서 제시하고 있는 검사실 내 정밀도 $2 \%$ 미만보다도 낮은 수치를 보이고 있어서 권고안을 만족하

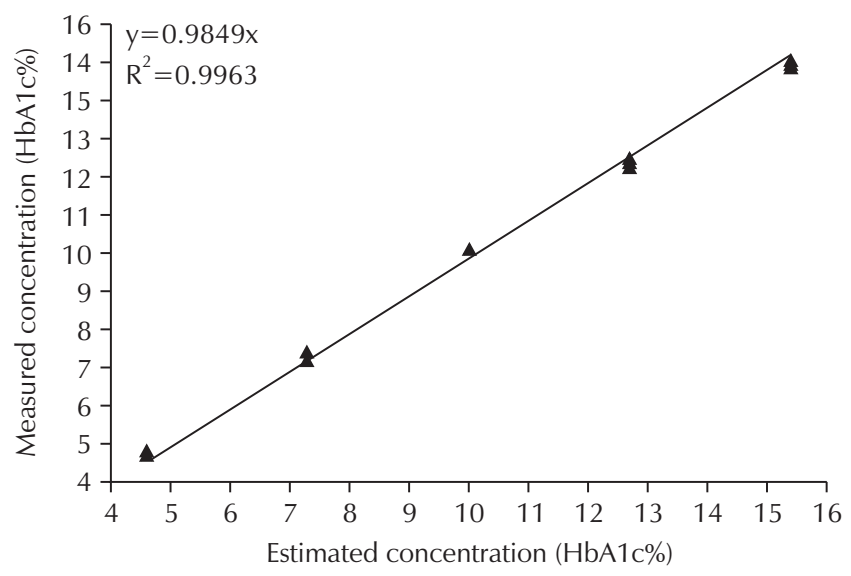

Fig. 1. Linearity of $\mathrm{HbA} 1 \mathrm{c}$ values using the D-100 hemoglobin testing system. Abbreviation: HbAlc, hemoglobin A1c.

Table 1. Precision of the D-100 hemoglobin testing system

\begin{tabular}{lccccccc}
\hline & \multicolumn{3}{c}{$\begin{array}{c}\text { International system of unit } \\
\text { (mean mmol/mol) }\end{array}$} & & \multicolumn{2}{c}{$\begin{array}{c}\text { National Glycohaemoglobin } \\
\text { Standardization Program unit (mean \%) }\end{array}$} \\
\cline { 2 - 3 } & Low (30.55) & Medium (45.94) & High (76.16) & & Low (4.9) & Medium (6.4) & High (9.1) \\
\hline Repeatability & $1.68(1.38-2.15)$ & $1.20(0.99-1.54)$ & $1.05(0.86-1.34)$ & & $0.95(0.78-1.21)$ & $0.99(0.81-1.26)$ & $0.80(0.66-1.02)$ \\
Between-day & $0.00(0.00-0.84)$ & $0.26(0.00-0.96)$ & $0.49(0.00-0.86)$ & & $0.00(0.00-0.47)$ & $0.45(0.15-0.75)$ & $0.38(0.00-0.66)$ \\
Within device & $1.65(1.51-2.06)$ & $1.45(1.27-1.81)$ & $1.16(1.03-1.40)$ & & $0.96(0.85-1.16)$ & $1.08(0.98-1.29)$ & $0.88(0.79-1.07)$ \\
\hline
\end{tabular}

Values are presented as CV\% (95\% confidence interval). 


\section{Journal of LABORATORY MEDICINE and QUALITY ASSURANCE}

Kyunghoon Lee et al • Performance Evaluation of D-100 HbA1c System

A

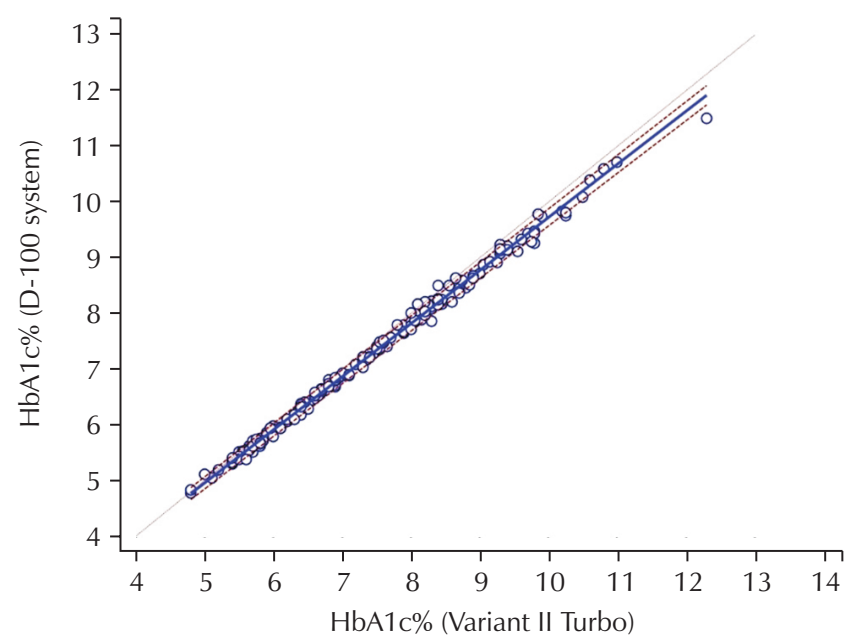

B

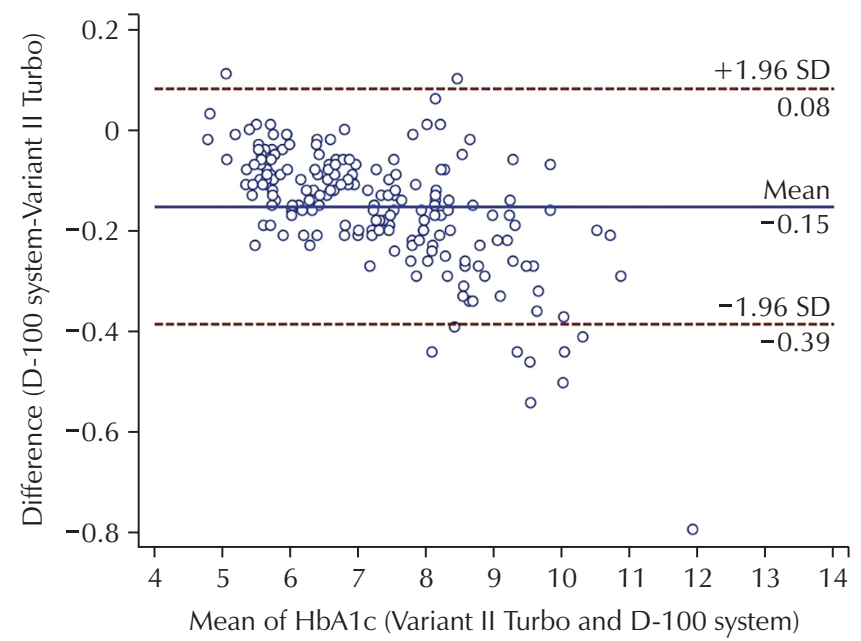

Fig. 2. Comparison of HbAlc levels obtained by the D-100 haemoglobin testing system (test) and the Variant II Turbo (comparative) by the Clinical Laboratory Standards Institute EP9-A3. (A) Scatter plots with ordinary linear fit with the PassingBablok regression analysis. (B) Bland-Altman plots. Abbreviation: HbA1c, hemoglobin A1c.

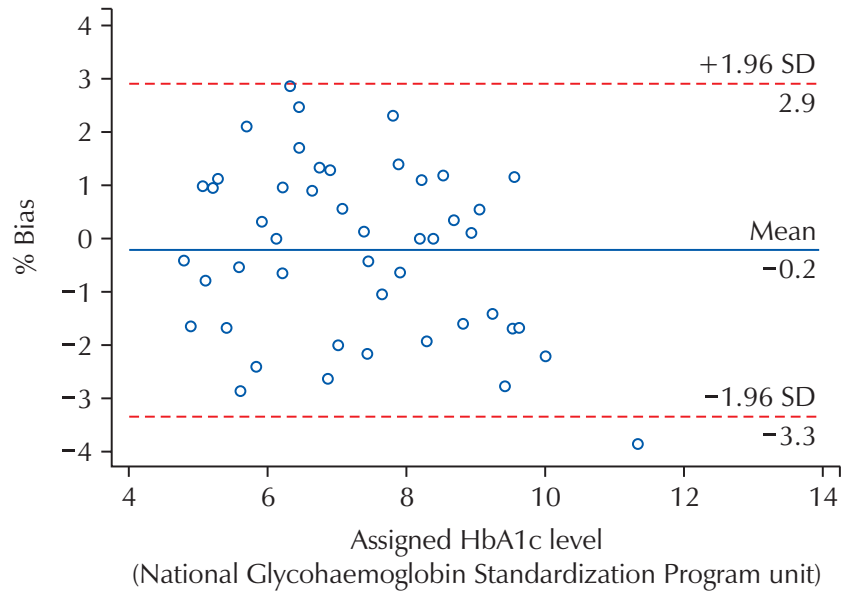

Fig. 3. Comparison of HbA1c levels obtained by the D-100 hemoglobin testing system (test) and assigned HbAlc levels by the Korea Centers for Disease Control and Prevention reference laboratory using Bland-Altman plots. \%Bias was calculated using the following formula: [(obtained $\mathrm{HbAlc}$ level-assigned $\mathrm{HbA1c}$ level)/assigned $\mathrm{HbA1c}$ level] $\times 100$. Abbreviation: HbA1c, hemoglobin A1c.

는 것을 확인할 수 있었다[10]. 그리고 기존에 보고된 동일 기 기와 다른 기기보다 작거나 비슷한 정밀도( $0.60 \%-1.46 \%)$ 를 가졌다[11-14]. 기존에 보고된 논문에서는 Bio-Rad사의 정도 관리물질을 사용하여 보다 넓은 범위 $(3.5 \%-19.0 \%)$ 의 직선성 을 평가하였다[11]. 본 연구에서는 환자 검체를 사용하여 상대 적으로 좁은 범위에서의 직선성을 평가하였지만 임상검사실
에서 검사를 수행하기에 충분한 넓은 범위로 생각된다. 검체 간 교차오염률은 기준치 $1 \%$ 보다 작은 값이어서 검체 간 교차 오염은 미미한 것으로 판단되었다. 동일한 방법으로 측정하는 Variant II Turbo와 비교하였을 때 상관계수(r)값이 0.998로 우수한 상관성을 보였다. 다만 Fig. 2의 (B) Bland-Altman plot에서 볼 수 있듯이 $\mathrm{HbAlc}$ 값이 $9.0 \%$ 에서 점점 증가할수 록 차이가 점점 증가하는 경향을 보였으며, 이러한 경향은 이 전의 보고에서도 동일하게 나타나고 있었다[11]. 그러나 의학 적 의사결정 농도인 $6.5 \%$ 와 $5.7 \%$ 에서의 추정 bias와 이에 대 한 $95 \%$ 신뢰구간은 각각 -0.11 ( -0.13 to -0.10$),-0.08$ (-0.09 to -0.06)으로 CLSI EP31-A-IR [15]에서 생물학적 변이를 고려한 $\mathrm{HbA} 1 \mathrm{c}$ 검사법 간의 허용 가능한 차이 $1.8 \%$ 를 기준으 로 계산한 각 농도의 허용 가능한 차이 0.11 및 0.10 과 비교하 였을 때, 두 검사법은 동등한 성능을 보였다.

질병관리본부 국가표준진단의학검사실에서 측정한 참값 과 D-100 system에서 측정한 결과의 일치도를 평가하였을 때 $9.0 \%$ 이상의 값에서는 값이 증가할수록 그 차이가 점점 증가하는 경향은 상관성 평가와 동일하게 나타나고 있었다. $\mathrm{HbA} 1 \mathrm{c} 11.0 \%$ 이상 한 검체에서는 $-3.3 \%$ 를 벗어났지만 $95 \%$ 신뢰구간 범위는 다른 연구에서 제시하고 있는 $\pm 6.7 \%$ 보다 낮았다[16]. Braga 등[17]은 optimal, desirable, minimum 총 허용오차(total allowable error)로 각각 $1.97 \%, 3.94 \%$, $5.92 \%$ 를 제시하고 있는데, desirable quality level보다는 작 은 값이어서 임상검사실에서 사용 가능한 것을 판단하였다.

우리나라에서 흔히 발견되는 헤모글로빈 변이로는 hemo- 


\section{Journal of LABORATORY MEDICINE and QUALITY ASSURANCE}

Kyunghoon Lee et al • Performance Evaluation of D-100 HbA1c System

globin G-Coushatta, hemoglobin Yamagata, hemoglobin Chad, hemoglobin Fort de France 등이 알려져 있고[18,19], 이들 변이가 $\mathrm{HbAlc}$ 결과에 미치는 영향에 대해 평가하였 다. Hemoglobin Yamagata 검체의 경우 bias값은 30.08\% (NGSP unit)로 매우 큰 값이었으며, 동일한 방법으로 사용 하고 있는 Variant II Turbo에서도 bias 값이 30.9\% (NGSP unit)로 비슷한 경향을 보였다. 그러나 이 경우 결과보고서에 'should not report HbA1c. Suspect variant, high HbA1c' 라는 flag note를 각각 확인하여 헤모글로빈 변이형에 대한 영 향을 인지할 수가 있었다. 그 외 다른 헤모글로빈 변이형에 대 한 bias는 상대적으로 낮은 값을 가지고 있었다. Hemoglobin $\mathrm{G}-$ Coushatta 10검체의 bias 평균과 표준편차의 값은 $-0.28 \%$ $\pm 0.24 \%$ (NGSP unit)이었으며, 기존의 보고된 이온교환 고 성능액체크로마토그래피법으로 측정하였을 때 나타난 bias의 값이 음의 값을 가지고 있었지만 값은 적었다[19]. 결과보고서 에서 hemoglobin G-Coushatta의 경우 'suspect variant'라는 flag note를, hemoglobin Chad의 경우에는 'should suspect variant peak $(\mathrm{s})>10 \%$ '라는 flag note를 각각 확인할 수 있 었기 때문에 헤모글로빈 변이형에 대한 영향을 인지할 수가 있었다. 하지만 hemoglobin Fort de France의 경우 아무런 flag note를 확인할 수 없었지만 참값과의 bias가 $0.16 \%$ 로 낮 아 문제가 되지 않았다. 전 세계적으로 더 흔한 hemoglobin S, hemoglobin $\mathrm{C}$, hemoglobin $\mathrm{D}$, hemoglobin $\mathrm{E}$ 에 대해서는 검 체를 확보할 수가 없어서 결과에 미치는 영향을 직접 확인할 수가 없었지만 기존의 연구에서 $\mathrm{HbAlc}$ 값이 위에 언급한 헤 모글로빈 변이체들에 의한 영향을 받지 않는다는 것을 확인하 였으며, carbamylated hemoglobin나 hemoglobin F에 의한 영향은 거의 받지 않는다고 보고하였다[11].

결론적으로 D-100 system은 높은 정밀도와 직선성 및 낮은 검체 간 교차오염률 및 다른 기기와의 우수한 상관성과 표준검 사실의 결과값과의 일치도를 나타내었으므로, 임상적으로 당 뇨병의 진단, 치료효과의 추적 관찰 및 합병증 예방을 위하여 $\mathrm{HbA1c}$ 의 결과를 적용할 수 있는 장비라고 판단된다. 또한 기 존 장비와의 우수한 상관성을 보이고 있으므로 기존의 장비를 충분히 대체할 만한 성능을 가지고 있다는 것을 확인할 수 있 었다.

\section{감사의 글}

본 논문은 분당서울대학교병원 위탁연구비(06-2015-020) 지원에 의해 이루어진 것이다.

\section{REFERENCES}

1. Wild S, Roglic G, Green A, Sicree R, King H. Global prevalence of diabetes: estimates for the year 2000 and projections for 2030. Diabetes Care 2004;27:1047-53.

2. Korean Diabetes Association, Korea Centers for Disease Control and Prevention. Diabetes fact sheet in Korea 2012. http://www.diabetes.or.kr/temp/Diabetes_Fact_ sheet2012.pdf (Accessed December 22, 2015).

3. American Diabetes Association. Standards of medical care in diabetes--2014. Diabetes Care 2014;37 Suppl 1: S14-80.

4. Trevino G. Consensus statement on the Worldwide Standardization of the Hemoglobin A1C Measurement: the American Diabetes Association, European Association for the Study of Diabetes, International Federation of Clinical Chemistry and Laboratory Medicine, and the International Diabetes Federation: response to the Consensus Committee. Diabetes Care 2007;30:e141.

5. Weykamp C. HbA1c: a review of analytical and clinical aspects. Ann Lab Med 2013;33:393-400.

6. Chung S, Jun SH, Song WH, Song J. Six years' experience of accuracy-based proficiency testing for $\mathrm{HbAlc}$ in Korea. J Lab Med Qual Assur 2015;37:92-100.

7. Clinical and Laboratory Standards Institute. Evaluation of precision of quantitative measurement procedures: approved guideline. 3rd ed. EP5-A3. Wayne (PA): Clinical and Laboratory Standards Institute, 2014.

8. Clinical and Laboratory Standards Institute. Evaluation of the linearity of quantitative measurement procedures: a statistical approach: approved guideline. EP6-A. Wayne (PA): Clinical and Laboratory Standards Institute, 2003.

9. Clinical and Laboratory Standards Institute. Measurement procedure comparison and bias estimation using patient samples: approved guideline. 3rd ed. EP9-A3. Wayne (PA): Clinical and Laboratory Standards Institute, 2013.

10. Sacks DB, Arnold M, Bakris GL, Bruns DE, Horvath AR, Kirkman MS, et al. Guidelines and recommendations for laboratory analysis in the diagnosis and management of diabetes mellitus. Diabetes Care 2011;34:e61-99.

11. Jaisson S, Leroy N, Guillard E, Desmons A, Gillery P. Analytical performances of the D- $100^{\mathrm{TM}}$ hemoglobin 


\section{Journal of LABORATORY MEDICINE and QUALITY ASSURANCE}

Kyunghoon Lee et al • Performance Evaluation of D-100 HbA1c System

testing system (Bio-Rad) for HbA1c assay. Clin Chem Lab Med 2015;53:1473-9.

12. Park HD, Kim HJ, Kim MS, Lee SY, Kim JW. Evaluation of hemoglobin A1c on the Cobas Integra 800 Immunoassay and Tosoh HLC-723 G8 HPLC Analyzer. J Lab Med Qual Assur 2009;31:239-46.

13. Kim T, Kim S, Chang HE, Song SH, Park KU, Song J, et al. Performance evaluation of HbAlc test on the Toshiba 200FR NEO using AutoLab HbA1c reagent. J Lab Med Qual Assur 2010;32:217-23.

14. Choi Q, Han M, Chang HE, Song SH, Park KU, Song J. Performance evaluation of the ADAMS A1c HA-8180 Analyzer for HbA1c. J Lab Med Qual Assur 2012;34:2530.

15. Clinical and Laboratory Standards Institute. Verification of comparability of patient results within one health care system: approved guideline (interim revision). EP31A-IR. Wayne (PA): Clinical and Laboratory Standards Institute, 2012.
16. Glad Working Group A1c Delegates WG, Mosca A, Branca MT, Carta M, Genna ML, Giorda CB, et al. Recommendations for the implementation of international standardization of glycated hemoglobin in Italy. Clin Chem Lab Med 2010;48:623-6.

17. Braga F, Dolci A, Montagnana M, Pagani F, Paleari R, Guidi GC, et al. Revaluation of biological variation of glycated hemoglobin $(\mathrm{HbA}(1 \mathrm{c}))$ using an accurately designed protocol and an assay traceable to the IFCC reference system. Clin Chim Acta 2011;412:1412-6.

18. Lee ST, Kim MS, Choi DY, Kim SK, Ki CS. Incidence of variant hemoglobin $(\mathrm{Hb})$ and increased fetal $\mathrm{Hb}$ concentrations and their effect on $\mathrm{Hb} \mathrm{Alc}$ measurement in a Korean population. Clin Chem 2006;52:1445-6.

19. Lee ST, Weykamp CW, Lee YW, Kim JW, Ki CS. Effects of 7 hemoglobin variants on the measurement of glycohemoglobin by 14 analytical methods. Clin Chem 2007;53:2202-5. 
당화혈색소 측정용 D-100 Hemoglobin Testing System에 대한 검사 성능 평가

이경훈 ${ }^{1,2} \cdot$ 김성민 ${ }^{3}$ - 전선희 ${ }^{3}$ 송상훈 ${ }^{1,2} \cdot$ 박경운 $^{1,3}$ • 송정한 ${ }^{1,3}$

${ }^{1}$ 서울대학교 의과대학 검사의학교실, ${ }^{2}$ 서울대학교병원 진단검사의학과, ${ }^{3}$ 분당서울대학교병원 진단검사의학과

배경: 당화혈색소(hemoglobin $\mathrm{A} 1 \mathrm{c}, \mathrm{HbA} 1 \mathrm{c})$ 는 당뇨의 진단 및 혈당 조절을 하는데 널리 쓰고 있 으며, 측정할 수 있는 다양한 방법이 있다. 이온교환 고성능액체크로마토그래피법을 이용하는 바이 오래드사의 D-100 HbA1c 전자동 측정기는 높은 처리율을 가지고 있다. 이 연구에서는 이 새로운 $\mathrm{HbA} 1 \mathrm{c}$ 측정기의 성능 평가를 하였다.

방법: Clinical Laboratory Standards Institute 가이드라인에 따라서 정밀도, 직선성, Variant II Turbo와의 상관성을 평가하였다. 검체 간 교차오염률과 질병관리본부 국가표준진단의학검사실에서 측정한 $\mathrm{HbA} 1 \mathrm{c}$ 참값과 차이를 평가하였다. 우리나라에서 자주 발견되는 헤모글로빈 변이형이 $\mathrm{HbA} 1 \mathrm{c}$ 결과값에 주는 영향을 평가하였다. Excel 2010 (Microsoft Co., USA)과 MedCalc ver. 14.12.0 (MedCalc Software bvba, Belgium) 프로그램을 이용하여 통계적 분석을 시행하였다.

결과: 검사 내 정밀도의 변이계수와 검사기기내의 변이계수는 National Glycohaemoglobin Standardization Program 및 international system of unit을 적용하였을 때 모든 농도에서 각 각 $1.08 \%$ 및 $1.68 \%$ 미만이었고, $4.6 \%-15.4 \%$ 범위에서 우수한 직선성을 보였다 $\left(R^{2}=0.996\right)$. Variant II Turbo와의 상관계수도 0.998로 높았다. $\mathrm{HbA1c}$ 참값과 차이는 $95 \%$ 신뢰구간이 $-3.3 \%-$ $2.9 \%$ 이었다. 헤모글로빈 변이형의 영향을 평가하였을 때 hemoglobin Yamagata 외에는 HbA1c 값에 크게 영향을 주지 않았다.

결론: D-100 system은 뛰어난 정밀성, 직선성, Variant II Turbo와 우수한 상관성을 가지고 있었으 며, 참값과의 일치도도 높았다. 그러므로 당뇨병을 진단하거나 치료 및 모니터링을 할 수 있는 충분한 성능을 보여주었다.

(J Lab Med Qual Assur 2016;38:95-101) 